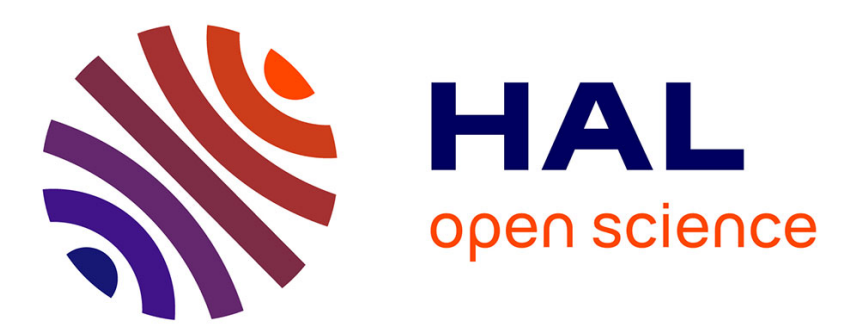

\title{
Towards a unified descriptive framework for industrial objective declaration and performance measurement
}

Lamia Berrah, Laurent Foulloy

\section{To cite this version:}

Lamia Berrah, Laurent Foulloy. Towards a unified descriptive framework for industrial objective declaration and performance measurement. Computers in Industry, 2013, 64 (6), pp.650-662. 10.1016/j.compind.2013.03.006 . hal-00870056

\section{HAL Id: hal-00870056 https://hal.science/hal-00870056}

Submitted on 8 Oct 2013

HAL is a multi-disciplinary open access archive for the deposit and dissemination of scientific research documents, whether they are published or not. The documents may come from teaching and research institutions in France or abroad, or from public or private research centers.
L'archive ouverte pluridisciplinaire HAL, est destinée au dépôt et à la diffusion de documents scientifiques de niveau recherche, publiés ou non, émanant des établissements d'enseignement et de recherche français ou étrangers, des laboratoires publics ou privés. 


\title{
Towards a unified descriptive framework for industrial objective declaration and performance measurement
}

\author{
Lamia Berrah, Laurent Foulloy \\ University of Savoie \\ Laboratoire d'Informatique, Systèmes, Traitement de l'Information \\ et de la Connaissance (LISTIC) \\ Lamia.Berrah@univ-savoie.fr, Laurent.Foulloy@univ-savoie.fr
}

\begin{abstract}
Expressing the performance of industrial companies is an important feature for their continuous improvement. As the performance concept refers to the objective one, our idea is to relate the performance expression mechanism to that of the objective declaration. We propose a variable tree framework to describe the break-down of objectives and the expression of the performances, highlighting the multicriteria aspect of both the performance and the objectives. Moreover, the temporal aspects of the objective declarations are emphasised, leading to the introduction of both the objective and the performance temporal trajectories. Such trajectories take into account the whole of the temporal horizon that is associated with the achievement of the objective. The link between the provided trees and trajectories is established through the elementary objective notion which corresponds to the leaves of the trees. A conventional recursive depth-first search algorithm is applied to the variable tree for the computation of the corresponding performances, at any considered milestone of the temporal horizon. Finally, the overall throughput time of the hydraulic cylinders manufacturing line of the Bosch Rexroth Company is considered to illustrate the proposed ideas.
\end{abstract}

\section{Keywords}

Industrial performance expression, objective breakdown, temporal trajectories, variable trees, recursive depth-first algorithm.

\section{Introduction}

Performance Measurement Systems (PMS's) have been an active field for several decades which has led to several literature reviews [1], [2], [3]. Performance measurement concept has a major place in such studies. In 1996, Neely et al. quoted: "Performance measurement is a topic which is often discussed but rarely defined." [4]. The authors proposed three definitions to differentiate the performance measure from the performance measurement and the performances measurement system. The performance measure is seen as "a metric used to quantify the efficiency and/or effectiveness of action". The performance measurement is "the process of quantifying the efficiency and effectiveness of actions". The performance measurement system is "the set of metrics used to quantify the efficiency and effectiveness of actions". Melnyck et al. defined a metric as "a verifiable measure, stated in either quantitative or qualitative terms and defined with respect to a reference point" [5]. Melnyck et al. pointed out two features. The first one concerns the process for converting data into measure which must be well-understood and documented. In this case the measure is said to be verifiable. The second one is to consider that metrics are measures which "capture characteristics or out-comes in a numerical or nominal form". The authors pointed out the necessity to compare the metric to a reference point in order to interpret its meaning: "The reference point acts as a basis of comparison, and can be an absolute standard or an internally or externally developed standard". 
From an organisational point of view, a PMS can be considered as being constituted from a set of interrelated Performance Indicators (PI's) [6]. Fortuin defined a performance indicator as " $a$ variable indicating the effectiveness and/or efficiency of a part or whole of the process or system against a given norm/target or plan" [7]. For Popova and Sharpanskykh, a PI is "a quantitative or qualitative indicator that reflects the state/progress of the company, unit or individual". The authors proposed a bench of attributes which characterise indicators and can be expressed in a formal language [8]. Relating PMS's and PI's, Lohman et al. wrote: "PM is the activity of measuring performance using PIs. A PMS is a system (software, databases, and procedures) to execute PM in a consistent and complete way" [9].

From this brief analysis, we can observe a consensus with regards to the different notions which are concerned with the performance measurement. As a summary, Browne et al. quoted that: " $a$ 'Performance Measure' is a description of something that can be directly measured (e.g. number of reworks per day). A 'Performance Indicator' is a description of something that is calculated from performance measures (e.g. percentage reworks per day per direct employee). 'Performance Measurement Data' are values or results for performance measures and indicators (e.g. the number of reworks per day $=36$ or the percentage reworks per day per direct employee $=2.4 \%$ ). A 'Performance Measurement System' is a complete set of performance measures and indicators derived in a consistent manner according to a set of rules or guidelines defined in the performance measurement system." [10]. Namely, the involved performance measurement process includes a kind of measure that is more or less translated into ratios, being implicitly referred to a target point. This target point is what is called the objective, i.e. the expected state to achieve by the considered system, while the measure is the real one.

Precisely, highlighting on the objective concept and its closeness with the performance one, Lebas mentioned: "performance is about deploying and managing well the components of the causal model(s) that lead to the timely attainment of stated objectives within constraints specific to the firm" [11]. Thus, while the performance idea refers to a kind of quality level, the objective idea comes to specify this level. Looking for the definition of the objective notion, from its declaration point of view, Keeney specified: "An objective is a statement of something that one desires to achieve. ... The degree of which an objective is achieved is measured by I what I refer to as an attribute. This definition of attribute is not universally used. Others have used terms such as measure of effectiveness, measure of performance, and criterion to define what I call an attribute" [12]. The links between performance and objective are also emphasized by Folan et al. in their survey about the use of the term performance [13]: "It is always made with a relevant objective in mind (thus, we commonly assess a company as per some set future vision on what the company wants to achieve, not on the objectives of some other body that is not the company).".

Nearly all PMS proposals reported in the literature are kinds of frameworks for linking strategic objectives, structuring tactical and operational criteria affecting them, and designing associated performance expressions [2], [14], [15], [16], [17]. As an illustration, one can mention that, at the beginning, with his "Performance Criteria System" Globerson [18] looked to handle the multicriteria aspect. He defined a PMS as a tool for the evaluation of the inputs, outputs, transformation and productivity in both manufacturing and non-manufacturing operations. Bititci et $a l$. term it an information system that is used to supervise performance, identify critical areas, enhance motivation, improve communication and strengthen accountability [19]. In their BSC Balanced ScoreCard approach, Kaplan and Norton introduced performance measures to provide their four famous perspectives (customer, internal, innovation and learning, financial) of a company [20]. However, in a previous analysis, we showed that PMS's usually cover, from a general point of view, the following main points [21]:

- Definition of the company area concerned by the PMS.

- Expression of the decomposition links between the strategic objectives and the elementary objectives (structured as a tree, matrix, graph...). 
- Definition of the way in which the associated "elementary" performances are expressed (physical measure, performance measure, performance evaluation).

- Choice of the aggregation tools used to obtain global performance expression, if any.

Most of the PMS's contributions generally focus on the decomposition links. Cause-effect tools such as the dependencies graphs, the cognitive map, the Value Focus Cycle Time, are used for the handling of the break-down of strategic objectives. It is the case, for instance, in the following: the QMPMS - Quantitative Model for Performance Measurement System [22], [23], [24], the IDPMS Integrated Dynamic Performance Measurement System [25], the AMBITE system - Advanced Manufacturing Business Implementation Tool for Europe or the SMART model - System Measurement Analysis and Reporting Technique - [26], or the PPMS - Process Performance Measurement System [27]. Information aggregation is not considered as a central a priori problem, but as an a posteriori one once elementary performances have been selected and defined. Moreover, according to the Taylorian concepts, expressing performance at the elementary level as well as the aggregated one, remains static, a posteriori of the execution of the action plan that is associated with the objective. The dynamic aspects of PMS's are indeed more related to the systemic life cycle of the involved measures, objectives and performance indicators. Objectives are revised, suppressed or added, leading thus to the same operations on the associated measures and indicators.

Subscribing to Lebas and Keeney points of view, we previously proposed a performance indicator model that essentially introduces the performance expression concept. By performance expression, we mean any kind of measure that gives information about the achievement of an a priori objective assignment [21]. The objective notion is thus identified to the target value that is declared by the decision-maker. To be more precise, PI's provide elementary performance expressions with regard to elementary objectives. Elementary objectives are those objectives that are not considered through their break-down. Elementary expression is the result of a comparison between the objective and the measure [28], [29]. A comparison function generalises, to some extent, the idea of metrics understood in its mathematical sense, that is, a function which defines a distance between two elements of a set ${ }^{1}$. Results provided by such comparison functions convey the idea of achievement: the closer the measure to the objective, the higher the objective achievement. Moreover, in order to handle the multicriteria aspect of the performance, we also proposed to consider that the performance expressions for strategic objectives are obtained by mathematical aggregation operators. The aggregation is made on the set of elementary expressions that are associated with the sub-objectives provided from the strategic objective break-down [21], [6].

Even if there is total agreement in the literature with regards to the link between the break-down and the declaration aspects of the objective, on the one hand, and the performance expression, on the other hand, to our best knowledge, what is missing is a descriptive framework that makes it possible to express the objective declaration and the performance expression in a coherent language, as close as possible to the mathematical one. Moreover, we can observe that the temporal dimension of the action plan is not totally handled in the way that the objectives are taken into account nor in the way that the performance is expressed. Indeed, the focus is on the target value associated to the end of the action plan and the performance is also a posteriori expressed. The aim of this paper is specifically to deal with the formal handling of these different considerations in a global framework. More precisely, in Section 2 we propose four requirements for such a framework. Formal temporal definitions of the objective as well as of the expression of a performance, either elementary or aggregated, are highlighted, generalising the static a posteriori performance expression. Section 3 addresses the implementation of the framework in the form of precise definitions associated with each requirement. In Section 4, a case study submitted by the Bosch Rexroth Company is addressed. Subscribing to continuous improvement, the company focuses on

\footnotetext{
${ }^{1}$ Let us note that we refer only to the idea of metrics since, in most cases, all conditions for a comparison function to be a metric are not fulfilled.
} 
the lean performances related to the throughput time strategic objective, with regard to the critical hydraulic cylinders line. According to their objectives declaration, decision-makers are looking for pieces of information on the potential reached performances, leading them to adjust the target values. Some concluding remarks and perspectives are finally proposed.

\section{Requirements for the framework}

Several aspects intervene in the definition of an overall framework that establishes a formal link between the objective declaration and break-down handling and the performance expression one. In this sense, four requirements are necessary according to us. The first two are related to the objective, respectively its declaration and its potential break-down, when its nature is multicriteria, generally at the strategic level. In order to take into account the temporal aspect, temporal objectives have to be introduced, which is translated into the third requirement. The last requirement thus concerns the definition of the performance expression model that may handle, over the time, both elementary and aggregated expressions.

\subsection{Defining objective attributes for its declaration}

From a general point of view, an objective is considered through a target value to achieve at a given time. This target value is associated to a decision criterion or an operational variable [30]. What we call the objective declaration concerns the step where the decision-maker gives this value as well as the necessary attributes to make it comprehensive, namely its universe of discourse. Moreover, for Ducq, an objective "must be expressed with a verb explaining the expected trend (i.e. to increase, to decrease, to maintain) associated to a considered performance domain (i.e. cost, quality, lead time, flexibility)" [31]. Nevertheless, objectives are often declared in natural language and a simple example is enough to show the complexity of such a declaration. For example, if the objective declaration is "Increase sales about $10 \%$ in six month", the variable "sales" is associated with this objective. For the sake of clarity, we need to retrieve at least the value, its unit, the final time but what is the unit of the sales? What is the meaning of "about 10\%"? Is "six months" a precise value or an approximate period?

In Computing with Words, Zadeh introduced the "precisiation" notion as a means for translating a human declaration into a formal homogeneous one, which is based on the association of a target value to a variable or criterion [32], [33], [34]. More precisely, by using this concept, the idea is to constitute the so-called universe of discourse related to the objectives [29], meaning the set of attributes that are required to characterise the objective. In Zadeh's precisiation, the meanings of terms are addressed, when needed, by means of fuzzy sets which are functions of variables. Sentences expressed in natural language are thus translated into mathematical expressions from which computation is possible. It leads to our first requirement for the framework.

Requirement 1: each objective is associated with a variable. The attributes of the objectives are "precisiated" by means of functions on the variable.

\subsection{Breaking-down strategic objectives}

Companies are characterised by multi-variable and multi-level objectives as well as actions, leading to complex and interacting organisations [35], [36], [37], [38], [39]. Systemic break-downs of overall strategic objectives are the most frequently carried out in order to obtain operational solutions [25], [27], [40]. As we have mentioned before, in their PMS's design, thanks to causeeffect thinking, decision-makers translate the decisional links into hierarchical objective trees in correspondence with the associated action plans. Since the objectives are associated with variables ${ }^{2}$,

\footnotetext{
${ }^{2}$ For the sake of homogeneity, we choose in this study to use the term "variable" rather than the "criterion" one.
} 
an objective tree is precisely the result of a quantification process on a variable tree. The variable tree becomes the central one that can be translated, beyond the objective tree, into action tree, measurement or performance tree.

Trees can be found in the value tree analysis (see for example [41], [42]), or other approaches dealing with hierarchies such as the Analytical Hierarchy Process AHP [43], [44], [45]. Breakingdown a strategic objective into a tree is a kind of recursive answer to the decision-makers' question concerning the achievement of the objective. Level by level, the question of achieving one objective is translated into achieving a set of objectives, such that the achievement of the latter ones means the achievement of the initial one. Contribution links are introduced between the objectives of one level and the sub-objectives of the lower level. Two semantics can be given to such a contribution, namely the satisfaction one and the physical one [12]. In the first case, the break-down consists of a translation of an overall objective into a set of fundamental objectives. In the second case, the break-down is more related to the physical means to consider for achieving the objective.

Assuming that an objective is elementary when the break-down is no longer necessary, that is, when its achievement is controlled and directly measured, the root of the tree is the variable identifying the strategic objective, the node variables the sub-objectives and the leaf variables the elementary objectives. This recursive vision of the break-down leads to our second requirement for the framework.

Requirement 2: the break-down involving the hierarchical dependencies between strategic objectives and their sub-objectives is represented by means of trees of quantified variables.

\subsection{Taking time into account in objectives}

In the practice of project management, highlighting the uncertainty and long-term aspects of the evolution of the action plans that are associated with the strategic objectives is well admitted. Decision-makers need intermediate pieces of information, along the temporal horizon, in order to react to the action plan evolution. Generally, the temporal horizon is first broken-down into a set of milestones that correspond to the evolutions of the associated actions plan or to budget control and allocation [46]. In this sense, milestones are introduced, and intermediate objectives are associated to them. This kind of break-down generally concerns elementary objectives, whose achievement is easier to control than the one of strategic overall objectives.

In the field of manufacturing processes, production can be linearly spread out. If intermediate objectives at given milestones are useful to control the objective achievement, the corresponding target values can be deduced from the a priori trajectory obtained by interpolation between milestones. For example, the temporal weekly or daily quantity objectives can be directly obtained from the linear interpolation, as shown in Section 3.3.2, using the intermediate objectives temporal trajectory of monthly sales increase. It leads to the third requirement for the framework.

Requirement 3: temporal elementary objective trajectories are defined by interpolating the intermediate objectives.

\subsection{Computing the performance expression}

According to its tree representation, computing the performance expression of a strategic objective can be considered from two points of view. The first one is based on a direct comparison of the measure to the objective. The second one concerns the indirect aggregation of the sub-objectives performance expressions. The major framework that is industrially used remains a multicriteria extension of the monocriterion Taylorian approach, where only financial measures were expressed, to a multicriteria expression [23], [6], [31], [47], [48], [49].

Conceptually, aggregation is a process which consists of producing a representative piece of 
information from several ones. The fields of multicriteria decision analysis and fuzzy sets have been very active in proposing methods, frameworks and operators. We can mention the methods provided by the MAUT (Multi-Attribute Utility Theory) and the MAVT (Multi-Attribute Value Theory), such as MACBETH, AHP or UTA [50], [51]. Such methods constitute sound frameworks for the elaboration of the aggregation operation. The most representative aggregation operator is the WAM operator - Weighted Arithmetic Mean - which is able to make compromises between the involved elementary performances. In previous works, our focus has concerned the Choquet integral, because of its property of handling interactions between the variables or criteria that are associated with elementary performances [6], [21].

However, the quantitative proposed approaches only focus on the performance expressions at the final assigned time. Another vision can be considered that consists of the performance expression along the temporal trajectory of the objective. The performance expression is no longer computed at the final time, but at any predefined milestone of the temporal horizon. This allows decision-makers to control more reactively the objective achievement, on the basis of what we call the temporal performance trajectory:

Requirement 4: the temporal performance trajectory is the performance expression all along the temporal objective trajectories.

\section{Framework modelling}

The nature of the proposed framework is descriptive, thus formalising the different steps to carry out in order to express the performance. Being translated into the four requirements previously introduced, these steps are now formalised. Hence, in this section, we choose to give a set of precise mathematical definitions which provide a modelling of the listed requirements, as well as a means for it their implementation on a computer.

\subsection{Objectives attributes and declaration}

Definition 1: Let $V$ be the set of variables to be potentially related to objectives. Any attribute of an objective is obtained through a function defined on $V$.

For example, let $v \in V, o(v)$ provides the target value of the objective. In the same manner, $T_{i}(v)$ and $T_{f}(v)$ respectively provide the initial and final dates for the objective action plan.

\subsection{Objective break-down}

Strategic objectives break-down is modelled by a composition of the following functions:

- The hierarchy function represents the tree of associated variables by sets of paths.

- The selection function is introduced to restrict the tree depending on the retained variables in the action plan.

- Tree transformations are proposed whose aim is to produce, from the tree resulting from the selection, another tree like, for example, the tree of target values.

Definition 2: Let $\mathcal{V}$ be the set of variables associated to the system under consideration. Let $A^{v_{0}}$ be a tree with a root $v_{0}$. The set $A \subset V$ is called a path if it contains the ordered list of the variables encountered from the root to a leaf of the tree.

Example 1: $A_{1}=\left\{v_{0}, v_{1}\right\}$ and $A_{2}=\left\{v_{0}, v_{2}, v_{3}\right\}$ are paths of the tree represented in Figure 1 but $A_{3}=\left\{v_{0}, v_{2}\right\}$ is not a path. 


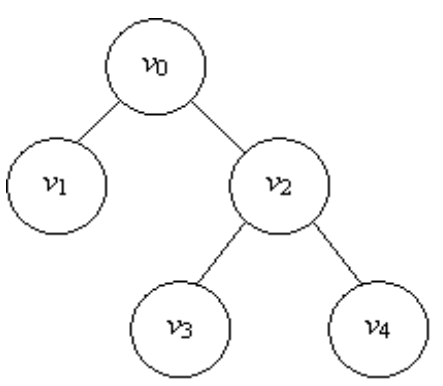

Figure 1: Example of a tree of variables.

Definition 3: The root of a tree associated with a strategic objective is called strategic variable. The set of all strategic variables is denoted $V_{s}$, with $V_{s} \subset V$.

\subsubsection{The hierarchy function}

Decision-makers look for an organised set of variables linked to the considered objective. Starting from the strategic objective and its associated variable, Definition 4 provides a formal representation of the process that leads to the tree of variables.

Definition 4: Let $V$ be the set of variables. The function $H$ which associates each strategic variable $v_{s} \in V_{s}$ with its tree $A^{v_{s}}$ is called the hierarchy function. Thus, $A^{v_{s}}=H\left(v_{s}\right)=\left\{A_{i}\right\}_{i \in I}$ where $A_{i}$ are paths of the tree.

Example 2: Using the hierarchy function, the tree represented in Figure 1 can be defined by $H\left(v_{0}\right)=\left\{\left\{v_{0}, v_{1}\right\},\left\{v_{0,}, v_{2}, v_{3}\right\},\left\{v_{0}, v_{2}, v_{4}\right\}\right\}$.

\subsubsection{The selection function}

The achievement of an overall objective can be obtained in different ways, with regard to the adopted strategy. Decision-makers restrict the previous complete variables tree to one that is based on the variables they select. This selection process (Definition 5) is not unique. Therefore, the original tree can be kept and different selections can be applied.

Definition 5: Let $V$ be the set of variables. Let $A^{v}{ }^{s}=\left\{A_{i}\right\}_{i \in I}$ be a tree where $A_{i} \subset V$ are paths of this tree. The function $S$ is called a selection function if $S\left(A^{v}{ }^{v}\right)=B^{v}{ }^{v}=\left\{B_{j}\right\}_{j \in J}$ where $B^{v}$ is a tree whose root is $v_{s}$ and paths $B_{j} \subset V$ are such that $\forall B_{j}, \exists A_{i} \in A^{v}{ }^{v}, B_{j} \subset A_{i}$.

Example 3: Referring to Figure 1, $S_{1}\left(H\left(v_{0}\right)\right)=\left\{\left\{v_{0}, v_{1}\right\},\left\{v_{0}, v_{2}, v_{3}\right\}\right\}$ or $S_{2}\left(H\left(v_{0}\right)\right)=\left\{\left\{v_{0}, v_{1}\right\},\left\{v_{0}, v_{4}\right\}\right\}$ are selections of the tree given by $H\left(v_{0}\right)$.

\subsubsection{Tree functions generated by functions on variables}

The hierarchy and the selection functions constitute intermediary steps to build the tree of the variables on which a further action plan processing will be performed. Definition 6 proposes a general tree transformation by applying the same function to each variable of the tree.

Definition 6: Let $V$ be the set of variables. Let $A^{{ }^{v} s}=\left\{A_{i}\right\}_{i \in I}$ be a tree where $A_{i} \subset V$ are paths of this tree with $A_{i}=\left\{v_{s}, v_{i_{1}}, \ldots, v_{i_{j}}, \ldots\right\}$. Let $f$ be a function defined on $V$. Then, we will say that $f$ 
generates a function $F$ on trees if $F\left(A^{v_{s}}\right)=A^{f\left(v_{s}\right)}=\left\{C_{i}\right\}_{i \in I}$ with $C_{i}=\left\{f\left(v_{s}\right), f\left(v_{i_{1}}\right), \ldots, f\left(v_{i_{j}}\right), \ldots\right\}$.

Figure 2 illustrates the transformation of the tree given in Figure 1 by means of the function $F$.

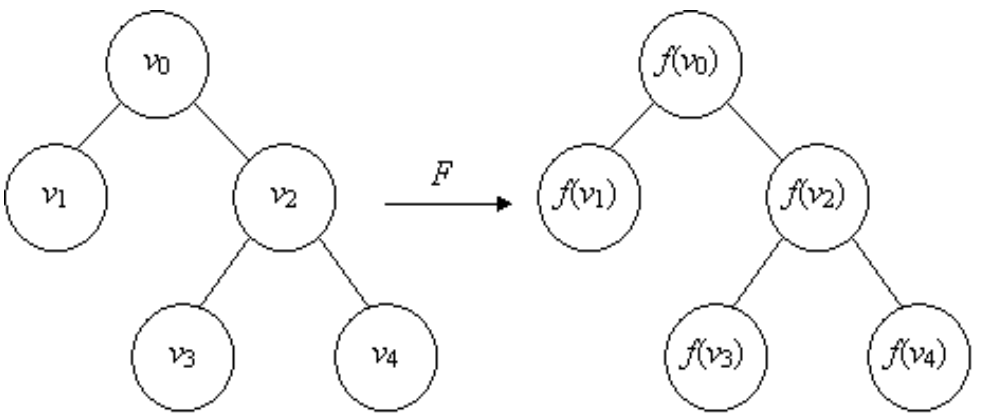

Figure 2: Function $F$ on a tree generated by the function $f$ on variables.

\subsubsection{Objective tree}

An interesting feature for the decision-maker is to represent the objectives associated with the variables, in the common sense of their target value. Definition 6 provides a way of obtaining this representation. The function $o$, given in Definition 1, generates a function $O$ which provides the tree of the target values. Given $v_{s} \in V_{s}$, the target value of a strategic variable is $o\left(v_{s}\right)$ if one considers only the variable, but it becomes $O\left(S\left(H\left(v_{s}\right)\right)\right)$ if one considers the whole tree. Figure 3 illustrates this concept on the variable $v_{0}$.

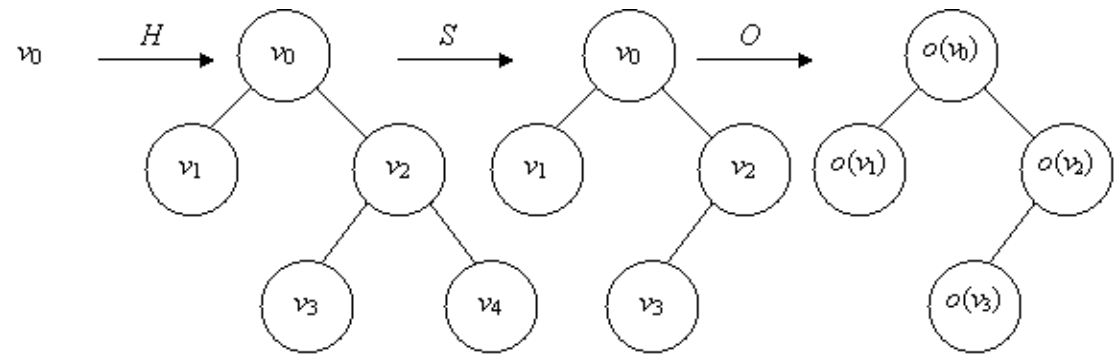

Figure 3: Composition of tree functions leading to the tree of objectives.

As a transition, let us recall that in the objective tree building process, the considered target value is the one to be reached at the end of the associated action plan execution. Another dimension is related to the evolution of the action plan, which can be translated into what can be called the temporal trajectory of the objective.

\subsection{Temporal objective trajectory}

\subsubsection{Intermediate objectives}

Definition 7: Let $V$ be the set of variables of the system under consideration and $v \in V$. The $i^{\text {th }}$ milestone associated with the variable $v$ in the action plan is defined by a function $t_{i}$ such that $T_{i}(v) \leq t_{i}(v) \leq T_{f}(v)$.

Definition 8: Let $t_{i}(v)$ be a milestone defined with regard to the target value of the objective which is associated with the variable $v \in V$. The intermediate objective at this milestone is given by $o_{i}(v)$ 
where $o_{i}$ is a function defined on $V$.

In industrial practice several milestones are used, thus defining the so-called temporal trajectory of the considered objective as follows.

Definition 9: The set of the couples $\left(o_{i}(v), t_{i}(v)\right)$ is called the intermediate objectives temporal trajectory of the objective that is associated to the variable $v \in V$.

Figure 4 illustrates an example of such a trajectory, described in a discrete universe, according to the objective "Increase sales by $10 \%$ in 6 months".

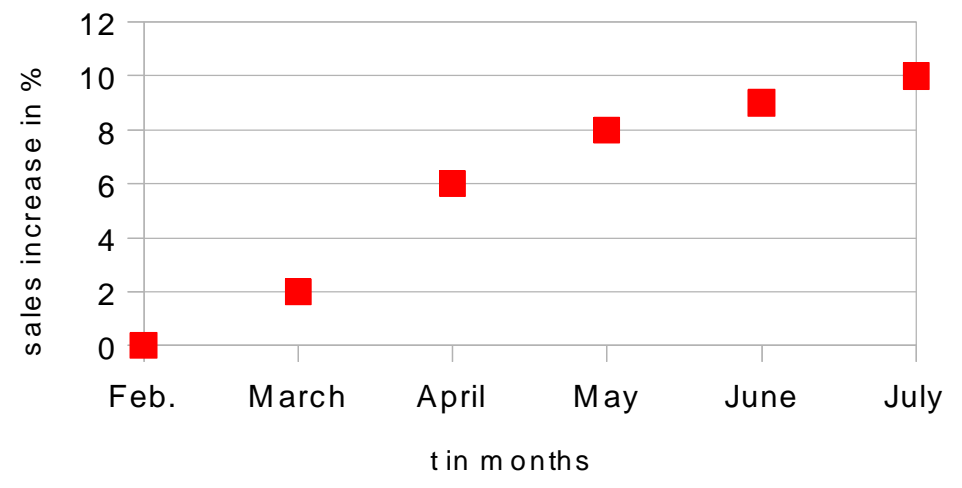

Figure 4: Example of intermediate objectives

\subsubsection{Temporal objective trajectory}

Definition 10: Let $V$ be the set of variables of the system under consideration and $v \in V$. The objective temporal trajectory is defined by the function $q$, called the quantification function, and $q(v, t)$ is the value of the objective associated with $v$ at the time $T_{i}(v) \leq t \leq T_{f}(v)$.

For example, from the intermediate objectives temporal trajectory of monthly sales increase given in Figure 4, the temporal weekly or daily quantity objectives can be directly obtained from the linear interpolation, as represented in Figure 5, by reading the trajectory y-axis for the given week or day. This concept can be generalised to any time $T_{i}(v) \leq t \leq T_{f}(v)$, the trajectory providing the quantification of the objective at this time.

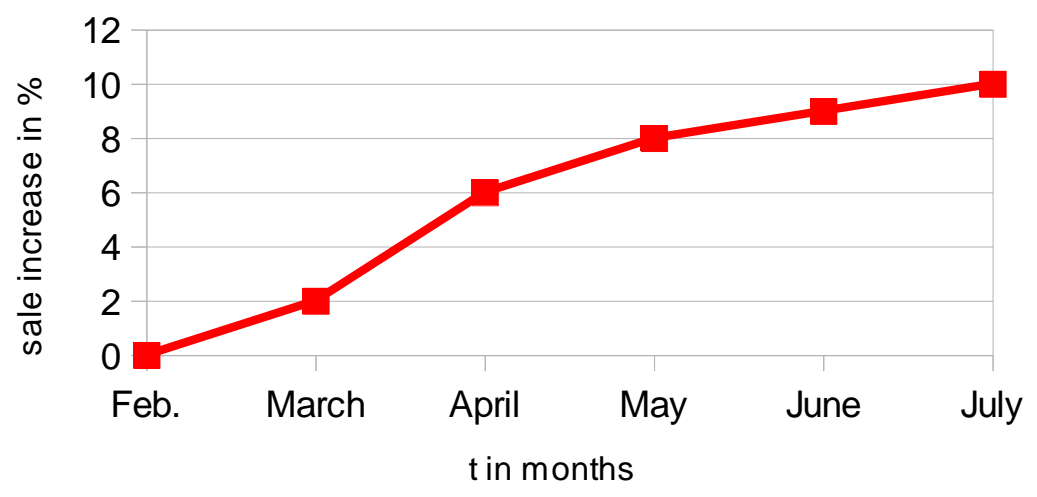

Figure 5: Example of objective temporal trajectory building.

According to Definition 10, let us note that the target value, given by the function $o$, is such that 
$o(v)=q\left(v, T_{f}(v)\right)$ and the intermediate ones $o_{i}(v)$ are such that $o_{i}(v)=q\left(v, t_{i}(v)\right)$.

Thanks to Definition 6, given a quantification function $q$, a tree of objective temporal trajectories can be built from a tree of variables as follows:

Definition 11: Let $V$ be the set of variables. Let $A^{v_{s}}=\left\{A_{i}\right\}_{i \in I}$ be a tree where $A_{i} \subset V$ are paths of this tree. Assume that the path $A_{i}=\left\{v_{s}, \ldots, v_{i, j}, \ldots\right\}$. The quantification of the tree $A^{v}$ is given by the function $Q$ such that $Q\left(A^{v^{s}}, t\right)=A^{q\left(v_{s}, t\right)}=\left\{C_{i}\right\}_{i \in I}$ with $C_{i}=\left\{q\left(v_{s}, t\right), \ldots, q\left(v_{i, j}, t\right), \ldots\right\}$.

In other words, the quantification of a tree is a tree whose root, nodes and leaves are the quantification of the variables at a given time $t$. Given a strategic variable $v_{s} \in V_{s}$, the tree of objective trajectories is given by the composition of the hierarchy, the selection and the quantification functions, that is $Q\left(S\left(H\left(v_{s}\right)\right), t\right)$. The objective temporal trajectory concept can be applied to each objective of a tree, as long as milestones and intermediates values are known. However, in practice, temporal trajectories are generally associated first to the elementary objectives, given their operational aspect.

\subsection{Performance expression computing}

Definition 12: Let $v \in V$ be a variable. The function $p$ is called the performance expression trajectory and $p(v, t)$ is the performance expression of the objective associated with $v$ at the time $t$.

As explained in Section 2.4, two cases are distinguished: elementary performance expression and aggregated performance expression. The former is monocriterion, and is obtained by directly comparing the objective to the measure while the latter relies on an aggregation. Indeed, the monocriterion performance becomes $p(v, t)=f(q(v, t), m(v, t))$ where $f$ is the comparison function and $m$ is the measurement function. Thus, $m(v, t)$ is the measured value for the variable $v$ at the time $t$. The multicriteria aggregated expression can be formalised by means of an aggregation function $A g$ such that $p(v)=A g(P)$ where $P=\left(p_{1}, \ldots, p_{i}, \ldots, p_{n}\right)$ and $p_{i}$ is the performance expression of the $i^{\text {th }}$ criterion. It can be extended to any time $t$, as $p(v, t)=A g(P(t))$ where $P(t)=\left(p_{1}(\mathrm{t}), \ldots, p_{i}(t), \ldots, p_{n}(t)\right)$.

Since our framework is organised into trees of variables, the aggregated performance expression is handled on nodes while the elementary performance concerns the leaves of the trees. Thus, under these hypotheses, the performance expression at each sub-objective level requires itself to compute the performance expression of the sub-objectives children and so on. In other words, computing the performance expression of a strategic objective is a recursive process applied on each node which is stopped when elementary objectives are reached. Therefore, the computation of the performance expression can be performed by a traversing tree algorithm. Since elementary objectives must be visited first, the conventional recursive post-order depth first algorithm has been used in our framework (see Figure 6). Each node is visited only once, it is useful to recall that its asymptotic complexity in time is linear with the number of nodes and the worst-case asymptotic complexity in space is $O(h)$ where $h$ is the height of the tree. 


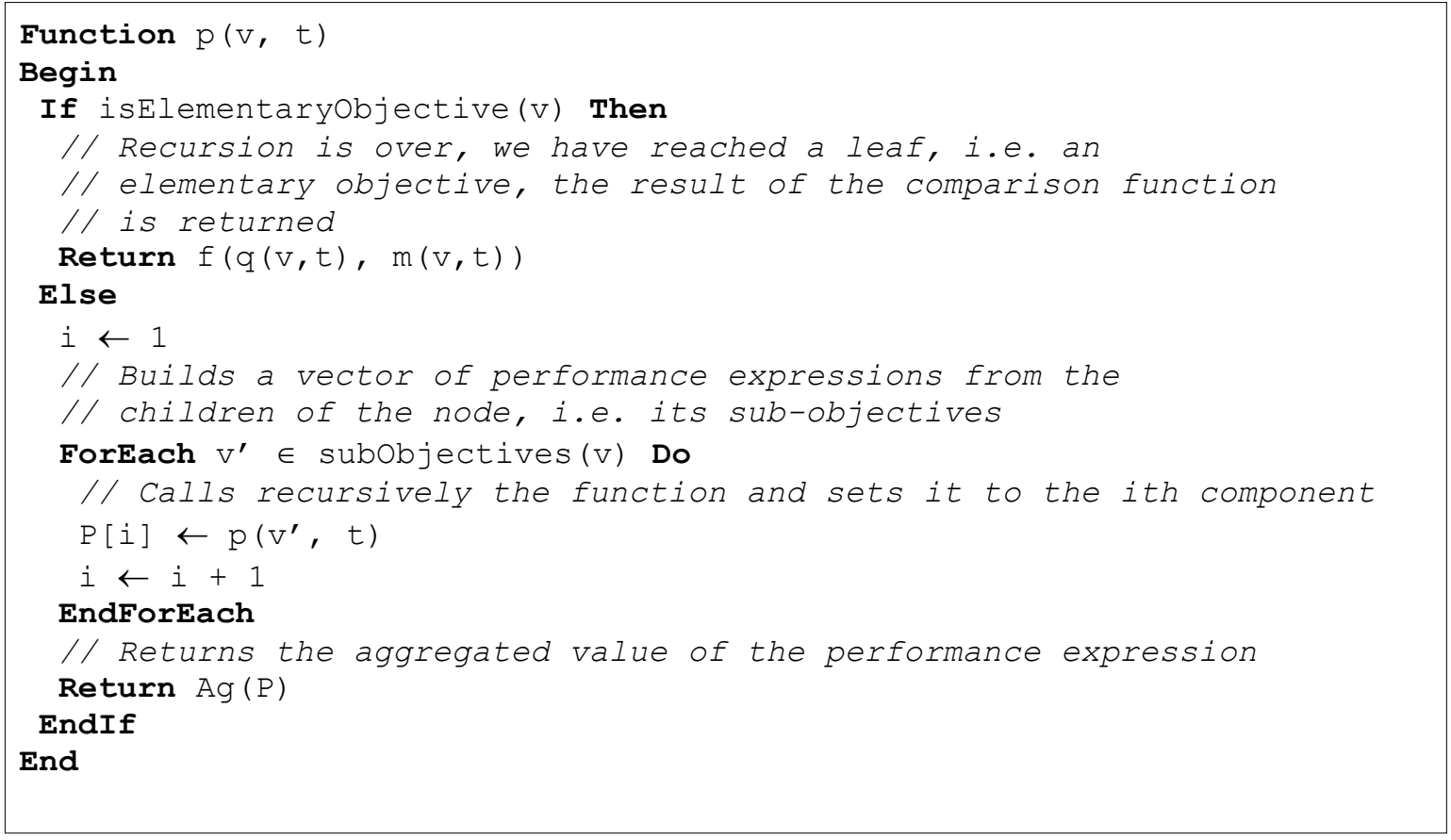

Figure 6: The performance expression algorithm.

Finally, the tree of temporal performance expressions is obtained exactly in the same way as the tree of objective trajectories described in Section 3.2.4 by means of Definition 6, using the performance function $p$.

\section{Case study}

The framework has been implemented in MATLAB and applied to a simulation test case, based on an industrial study that has been suggested by the French business unit of the Bosch Rexroth Company ${ }^{3}$. Hence, before considering the throughput time objective performance expression let us first briefly present the industrial system and detail the submitted problematic.

\subsection{The company's industrial system}

The Bosch Rexroth Company is a world leader in industrial automation. It designs, produces and delivers pneumatic, hydraulic and mechanical components. The business unit in France designs and produces cylinders and distributors for automation with about 400 employees and a turnover of about $€ 60$ million. The company manufactures standardised items $(1,300,000$ pneumatic distributors, 170,000 pneumatic cylinders, 28,500 hydraulic cylinders) and customised items (32,000 pneumatic distributors, 16,000 pneumatic cylinders and 3900 specific products). The variety of products is very wide especially concerning the hydraulic cylinders (a few million possibilities). The manufacturing process is weakly automated, consisting of activities of manufacturing, assembly, finishing, packaging and dispatching. The product is made of about 15-25 elementary parts. The manufacturing cycle time is between two and ten days. The production management consists of business planning for product families and Kanban for the component supply.

Since the beginning of the 80 s, the company has progressively adopted continuous improvement

3 A partnership is established between the company and the LISTIC laboratory, leading, from an academic point of view, to Phd theses and international publications. That is why the industrial system description is quite similar to the one given in [53]. For the sake of confidentiality, the considered values are purely indicative. 
approaches. These concern the classical performance criteria such as quality, productivity, safety, and environment and include the logistics, management and lean manufacturing aspects. The performance system is based on the conventional tools of continuous improvement. It focuses on employee training and the cultural aspects of the lean philosophy. More particularly, since a few years, the company has subscribed to an overall strategy of improving the lean objectives satisfaction related to the manufacturing throughput time, meaning "the length of time between the release of an order to the factory floor and its receipt into finished goods inventory or its shipment to the customer" [52]. Involving more than one operation duration, the throughput time objective is considered as complex in its achievement, depending on the achievement of different objectives, particularly the ones that are analysed as critical with regard to the context and the strong and weak points of the considered system.

For the sake of conciseness, the considered physical system is the Hydraulic Cylinders (HC) (see Figure 7).

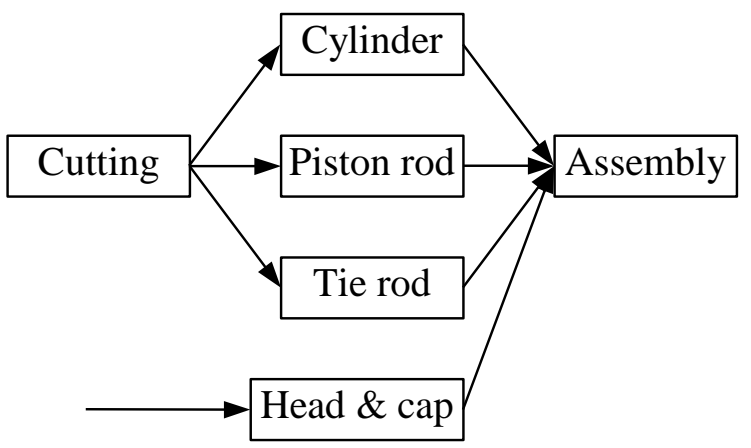

Figure 7: The hydraulic cylinder Line.

Decision-makers looked first for a better explanation of the current situation [53]. Although several action plans have been launched in order to increase the lead time, the current state of the HC line needs more improvement, in terms of working, regarding the takt time, the delays related to the supply service, the lack of synchronicities in the different involved processes...

The throughput time performance is multicriteria and is planned to be reached at the end of a relatively long temporal horizon ( 2 years). In order to better react to what could happen along the action plan execution, the break-down of the objective that is related to the delivery time is realised, highlighting, moreover, the dependencies between the involved variables. Indeed, according to the decision-maker expertise, more or less strong links are established between the variables (see Figure 8). 


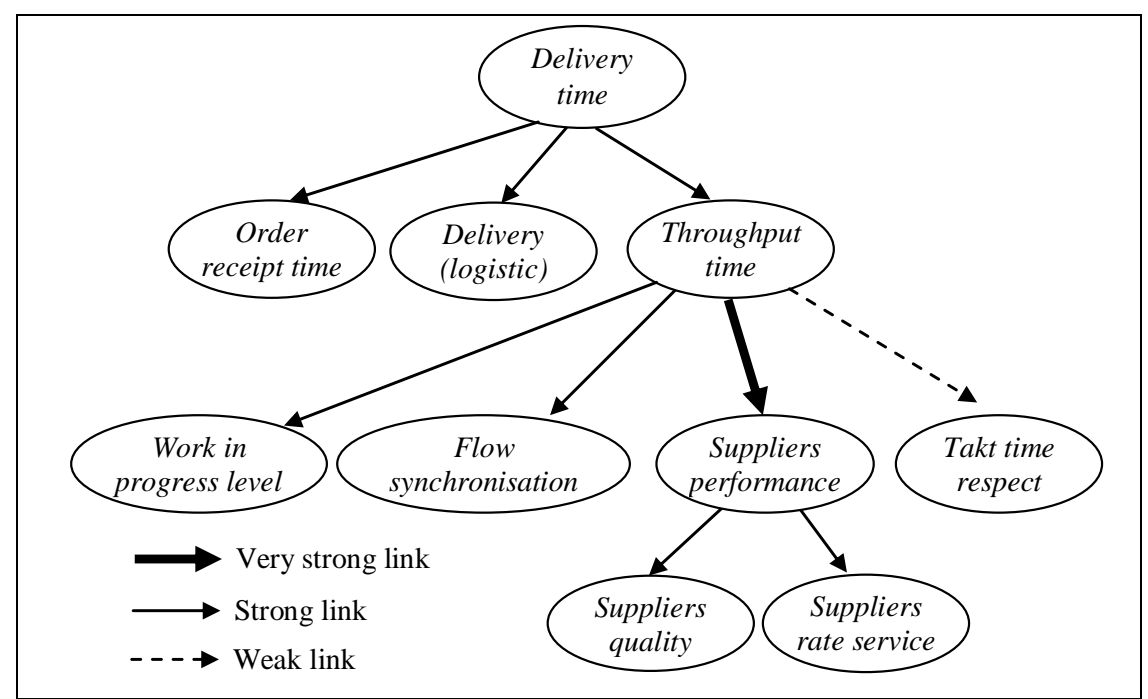

Figure 8: The delivery time break-down in the Bosch Rexroth company

We are now looking for the adjustment of the objective break-down with regard to the potential reached performances, along the two-year temporal horizon. In this sense, by considering the knowhow of the decision-makers, we will first consider the throughput time objective breakdown. Then, temporal performance scenario simulations will be suggested, providing the decision-makers with pieces of information about the evolution of the objectives being reached. We only present here the two extreme cases, which correspond to the situations where respectively "everything goes right" and "nothing goes right", with regard to the required conditions for the action plan execution.

\subsection{The throughput time improvement}

One main problem persists, which is related to a too high throughput time (see Figure 9).

Throughput time (in days)

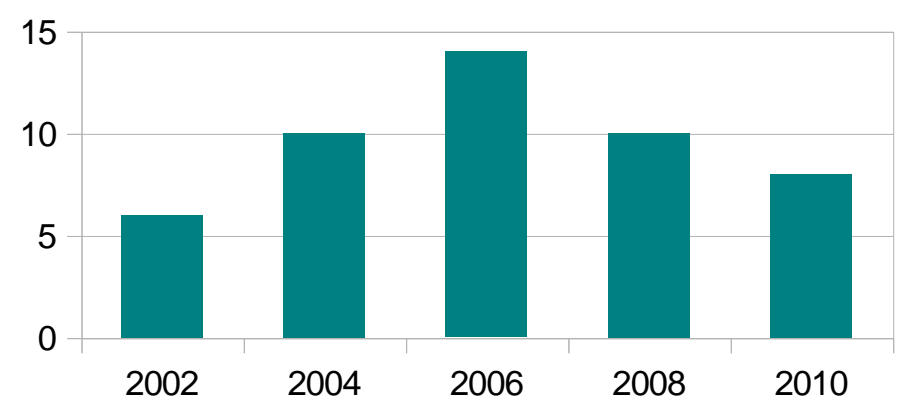

Figure 9: The manufacturing throughput time evolution.

According to the established diagnosis, decisions-makers decide to reinitialise the improvement process by reconsidering first the throughput time objective break-down, looking thus to check the validity of the sub-objectives tree, with regard to the real situations. The overall throughput time target value has been maintained at 3 days, to be reached in a temporal horizon of 12 months.

After the hierarchisation and the selection operations (see Sections 3.2.1 and 3.2.2), the following variables are considered, leading to the variable tree given in Figure 10:

- the work-in-progress WIP level, which is identified by the mean number of HC in the plant;

- the flow synchronisation, which describes the time difference between the flows in the HC line (see Figure 7);

- the suppliers performance which has itself two sub-objectives, the suppliers quality 
representing the number of parts with defects (expressed in $\mathrm{ppm}$ ) and the service rate of the suppliers, which represents the ratio of components delivered on time by suppliers with regard to the total number of components to be delivered by them;

- the respect of the takt time, which is the required time for a product to go out of the production line.

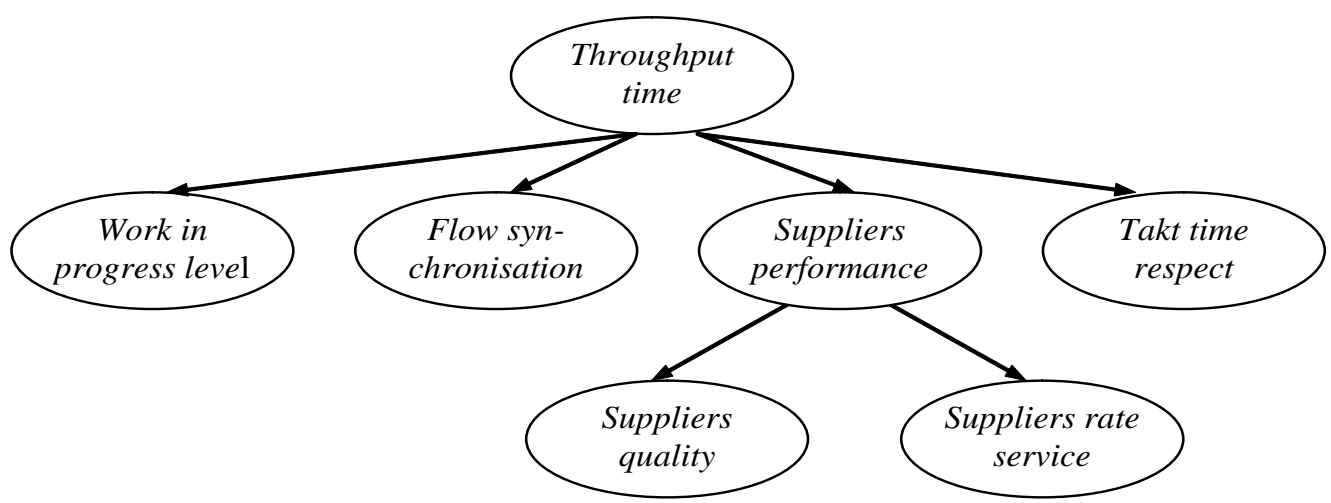

Figure 10: The throughput time variable tree.

The elementary objectives are also quantified by the HC line decision-maker .The description of the current value and the objective quantification, that is, the target value, are given in Figure 11.

\begin{tabular}{c|c|c}
\hline Objective variable & Target value & Current value \\
\hline throughput time & 3 days & 8 days \\
\hline work in progress level & 1 day & 5 days \\
\hline flow synchronisation & 0 day & 3 days \\
\hline suppliers service rate & $100 \%$ & $4000 \mathrm{ppm}$ \\
\hline suppliers quality & $500 \mathrm{ppm}$ & $0.125 \mathrm{hh}$ \\
\hline takt time (respect) & $0.100 \mathrm{hh}$ & \\
\hline
\end{tabular}

Figure 11: Current values and objective target values in the throughput time breakdown.

\subsection{Simulation of the performance trajectories}

The performance expression of the throughput time cannot be directly obtained. It can be computed from the tree of variables resulting from its break-down, using the recursive algorithm given in Figure 6 . The depth-first search algorithm processes elementary objectives before aggregating their performance expressions. Let us recall that, at any time $t$ and for each variable $v$ associated with an elementary objective, the elementary objective performance expressions are obtained by comparing the measurement $m(v, t)$ with the corresponding quantified value $q(v, t)$. The quantified values are obtained from the respective current and target values of the elementary objective given in Figure 16. It has been assumed that a linear interpolation between these two limits was acceptable. The target values are supposed to be reached within two years, that is, 96 workingweeks for the company.

In the industrial context, the behaviour of a plant is often simulated in order to analyse the effect of the action plans. The measurement functions $m$ are supposed to model the effect of the action plan associated with the throughput time objective. Obviously, manufacturing conditions are not always ideal and random events often occur which make simulations only a rough approximation of the real industrial context. 
Let $x$ be a variable of the throughput time variable tree. Let $w_{k}$ represent the $k^{\text {th }}$ week. According to the denotations introduced in the previous sections, we have $w_{0}=T_{i}(x)$ and $w_{96}=T_{f}(x)$. Now, let us assume that the manufacturing conditions are regular, meaning that there are no random events that may affect the action plan execution. In such an ideal case where the system is fully performing, the simulation of the measurement function must exactly follow the temporal objective trajectory, which is a linear interpolation between the current value $q\left(x, T_{i}(x)\right)$ and the target one $q\left(x, T_{f}(x)\right)$ along the temporal horizon. It leads to:

$m\left(x, w_{k+1}\right)=m\left(x, w_{k}\right)+\Delta$ with $\Delta=\frac{q\left(x, T_{f}(x)\right)-q\left(x, T_{i}(x)\right)}{T_{f}(x)-T_{i}(x)}$.

For $k=0$, the function is initialised with the current value, i.e. $m\left(x, w_{0}\right)=q\left(x, T_{i}(x)\right)$.

We have chosen to represent random events by means of a multiplicative noise leading to the following simulation model of the measurement function:

$q\left(x, w_{k+1}\right)=q\left(x, w_{k}\right)+\Delta * \varepsilon$ with $\varepsilon=k(x) *$ rand (1) where rand (1) is a pseudo-random number in the interval $[0,1]$ and $k$ a constant value depending on the variable $x$.

The mean value of the pseudo-random generator is assumed to be 0.5 , therefore when $k(x)=2$, the measurement is close to the objective temporal trajectory. Taking $k(x)<2$ (resp. $k(x)>2$ ) leads to measurements above (resp. below) the objective trajectory if it is decreasing or below (resp. above) if it is increasing. An illustration of the effect of this parameter is given in Figure 12 for the variable work in progress level.

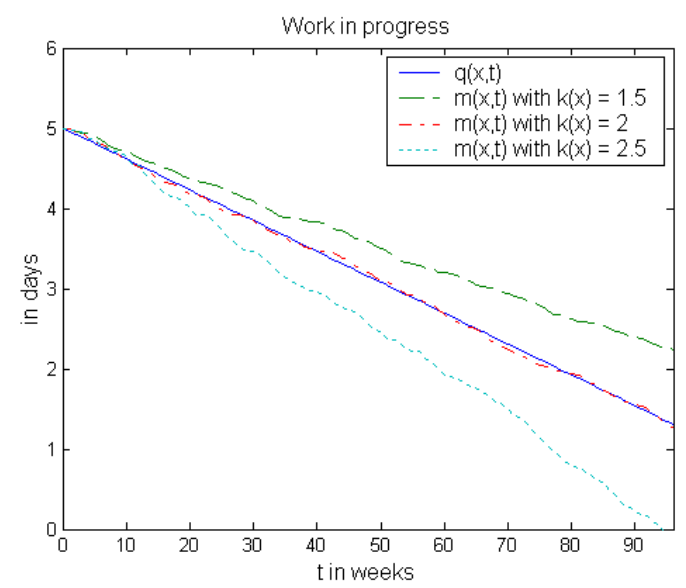

Figure 12: Effect of the parameter $k(x)$.

It has been chosen to compute the performance expression of the throughput time with a conventional Weighted Arithmetic Mean, that is $W A M_{w}(x)=\sum x_{i} w_{i}$ with $x=\left(x_{1}, \ldots, x_{4}\right)$ the vector of the values to aggregate which are respectively related to the work in progress level, the flow synchronisation, the suppliers performance and the takt time respect and $w=\left[\begin{array}{llll}\frac{4}{28} & \frac{11}{28} & \frac{6}{28} & \frac{7}{28}\end{array}\right] 4$.

4 These coefficients have been previously computed, in the context of the collaboration with the company. Decisionmakers have considered these results to be still valid, since the fixed target values are almost the same. 
The suppliers performance is the result of the aggregation of the sub-objectives performances also using a Weighted Arithmetic Mean with a weight vector $w=\left[\begin{array}{ll}0.4 & 0.6\end{array}\right]$. This means that the suppliers service rate performance is considered as more important than the suppliers quality one. This result is natural, with regard to the company context; it is in fact important to have the parts delivered at the maximum rate.

These variables are associated with elementary objectives whose performance expressions are obtained by means of the distance-based comparison functions. A distance provides a result in $\mathfrak{R}^{+}$. When the target is equal to the measurement, i.e. the distance is equal to 0 , it corresponds to the best performance expression. The higher the distance, the worse the performance. Therefore, by a transformation of the distance, we retrieve behaviour of the performance expression in the interval $[0,1]$ where 0 is the worse and 1 the best. Let $u=|m(v, t)-q(v, t)|$ be the distance between the measurement and the objective. The following comparison functions have been used: $f_{2}(u)=\mathrm{e}^{-c \cdot u}$, $f_{3}(u)=\frac{\frac{\pi}{2}+\arctan (-u+c)}{\frac{\pi}{2}+\arctan (c)}, f_{4}(u)=\frac{1+e^{-\lambda c}}{1+e^{\lambda(u-c)}}$ with $u=|m(v, t)-q(v, t)|$. As shown in Figure 13, a tree of functions for the performance expression computation and a tree of related parameters are associated with the tree of variables given in Figure 10 according to Definition 6.
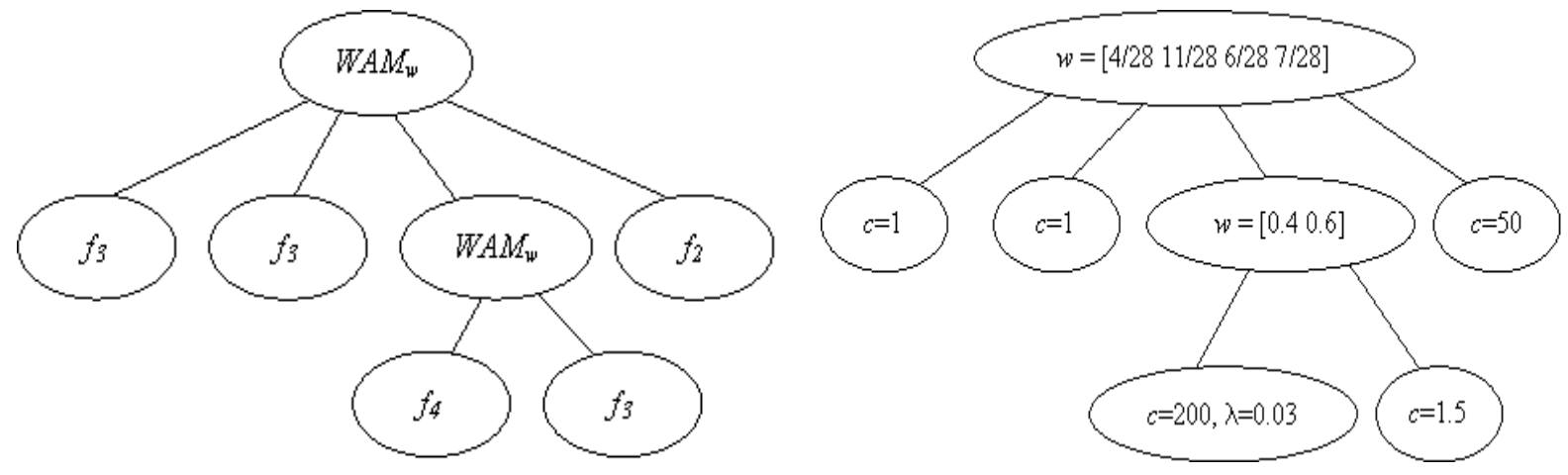

Figure 13: The trees of functions and parameters for the performance expression computation.

In order to obtain an idea of the performance expression trajectory, two cases identifying the previously described situations, and thus relying on two different sets of parameters, are considered in the next section.

\subsection{Simulation results}

\subsubsection{Case 1: regular manufacturing conditions}

First, let us analyse the case where $k(x)=2$ for all the variables associated with the throughput time. The objective temporal trajectories and the generated measurements are represented in Figure 14. 

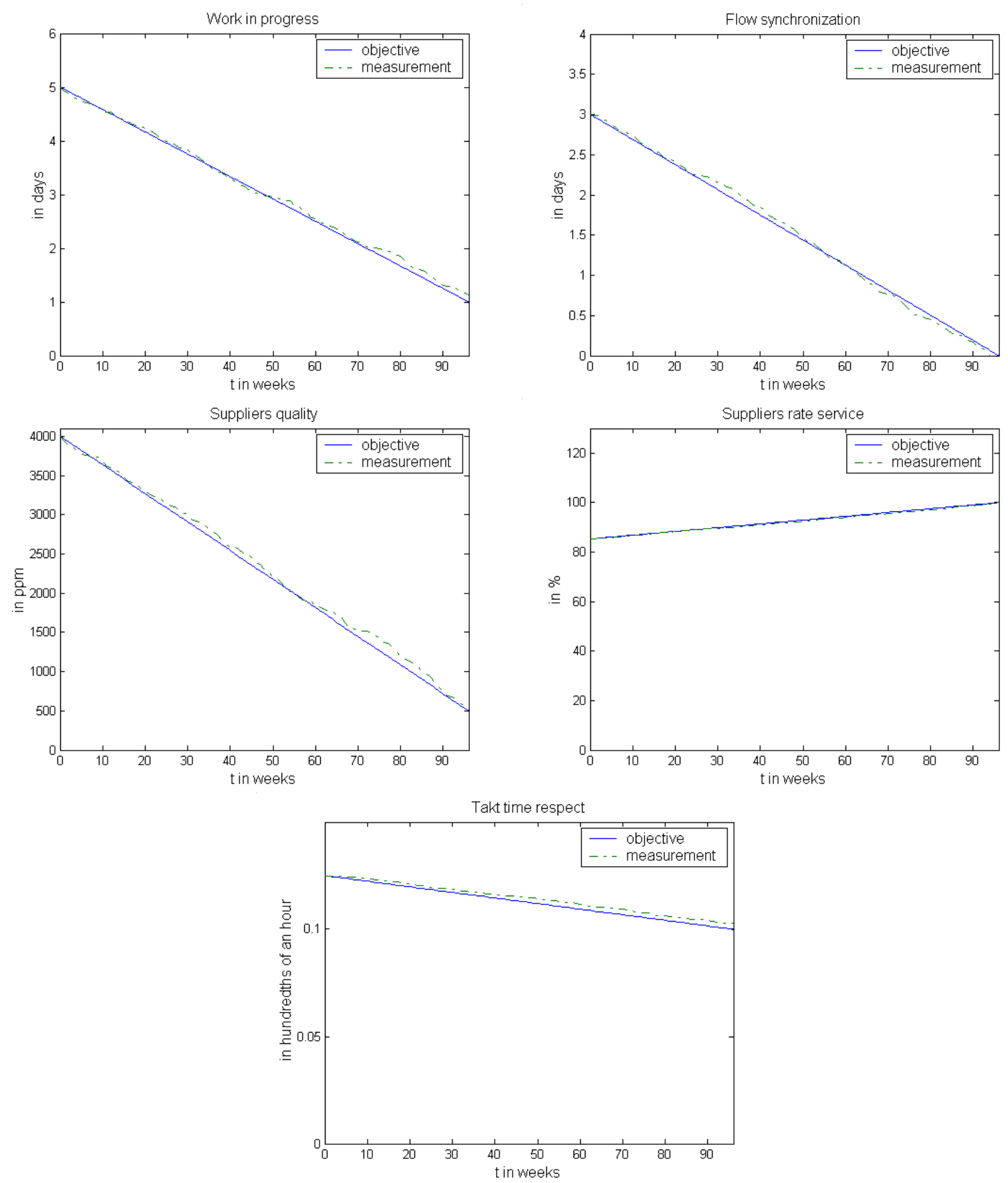

Figure 14: Objective temporal trajectories and measurements associated with the throughput time breakdown.

The throughput time performance trajectory resulting from the aggregation of the elementary objectives performance is given in Figure 15. As can be observed, the performance trajectory is close to 1 meaning that the behaviour of the plant is close to the expected one. 


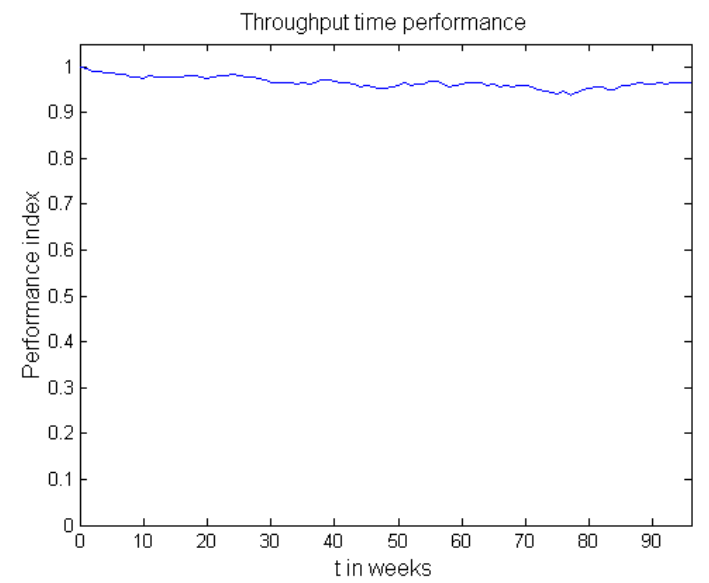

Figure 15: The throughput time performance expression trajectory.

\subsubsection{Case 2: irregular manufacturing conditions}

In order to simulate irregular manufacturing conditions, the parameters $k(x)$ must be taken below or equal to 2. The parameters given in Figure 16 generate measurement functions above the temporal objective trajectories for the variables work in progress level, flow synchronisation and takt time respect and below it for the suppliers service rate.

\begin{tabular}{|c|c|}
\hline Variables & $k$ \\
\hline work in progress level & 1.5 \\
\hline flow synchronisation & 2 \\
\hline suppliers quality & 2 \\
\hline suppliers service rate & 1.8 \\
\hline takt time respect & 1.5 \\
\hline
\end{tabular}

Figure 16: Coefficients for the measurements simulation.

The objective temporal trajectories and the generated measurements are represented in Figure 17. 

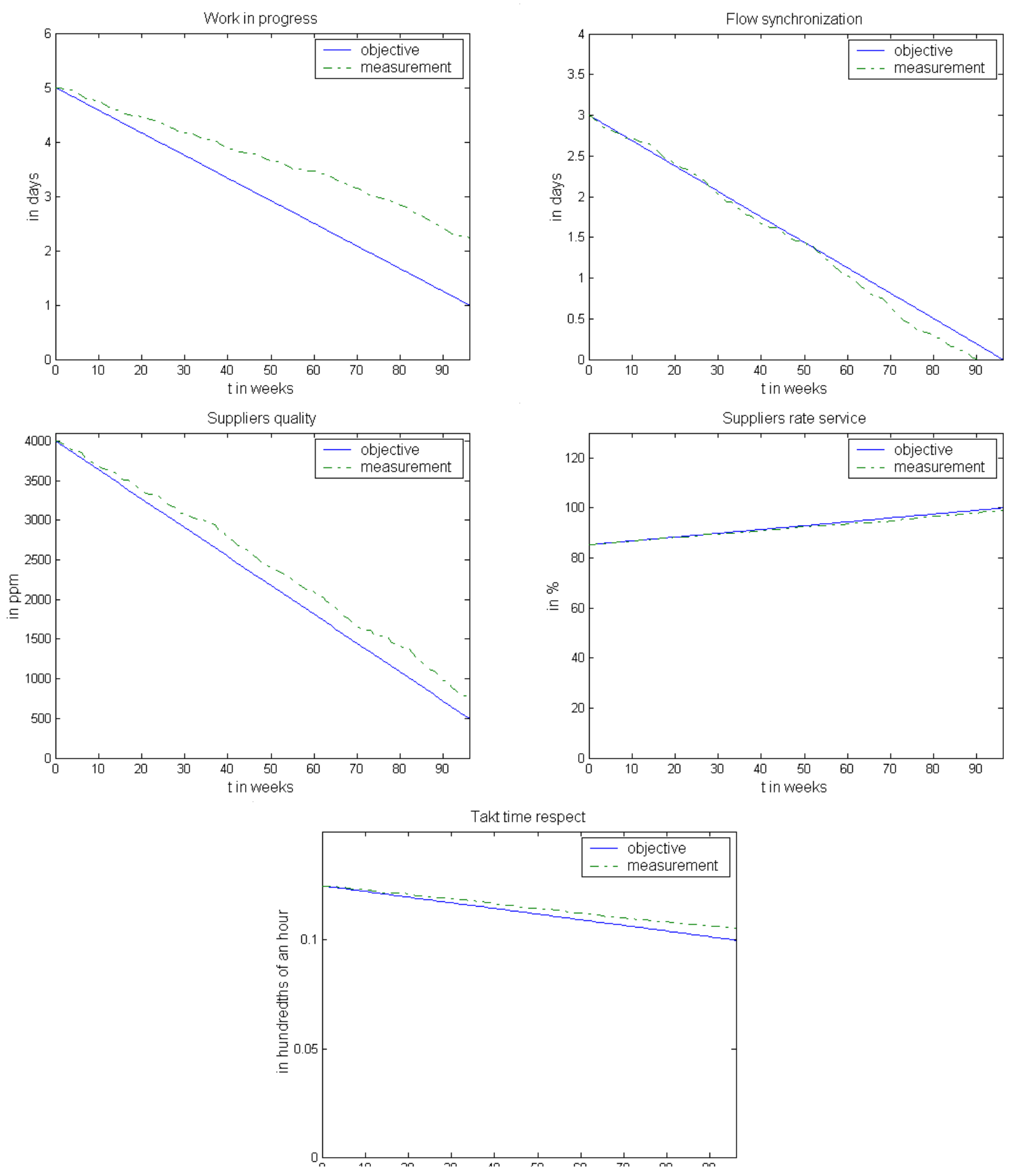

Figure 17: Objective temporal trajectories and measurements associated with the throughput time break-down.

The throughput time performance trajectory resulting from the aggregation of the elementary objectives performance is given in Figure 18. 


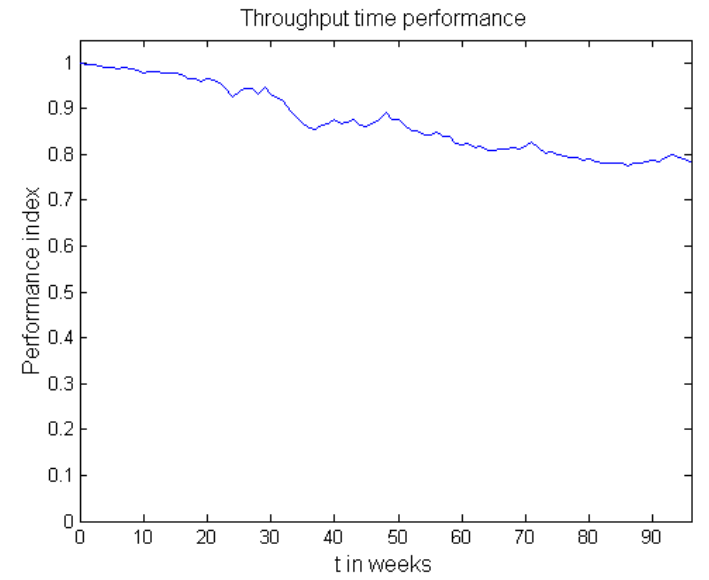

Figure 18: The throughput time performance expression trajectory.

As can be observed, the performance trajectory of the throughput time is globally decreasing. This result can be used to react before the end of the action plan. Assuming that the optimal performance is defined by a performance expression equal to 1 , accepting a variation of $15 \%$ for example, i.e. a threshold equal to 0.85 , makes it possible to detect abnormal behaviour of the system under consideration at week 50 .

Because the computation relies on a recursive algorithm, at any time all information is available at any level of the tree. The performance trajectories of the elementary objectives are shown in Figure 19. 

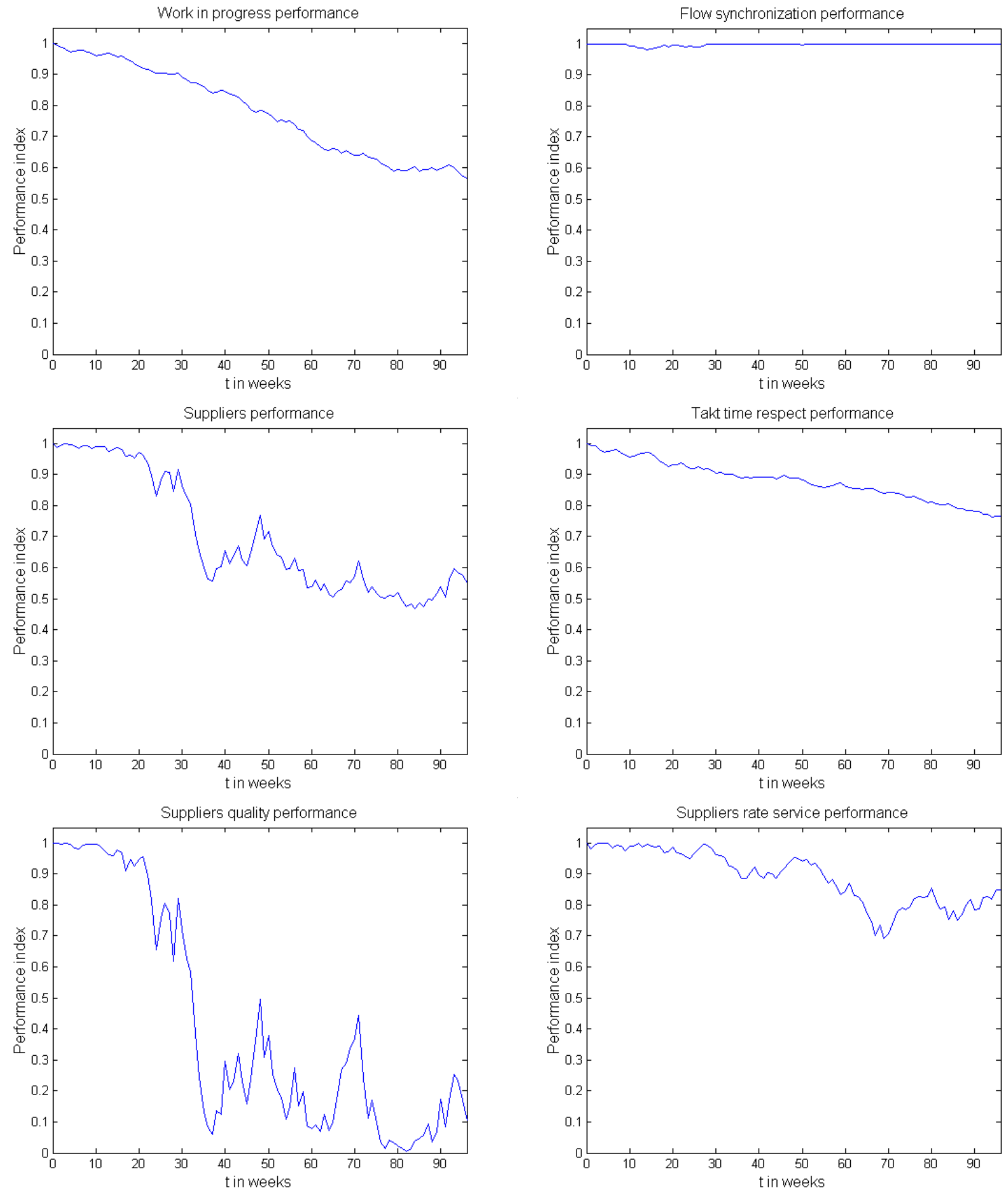

Figure 19: Performance expression trajectories of the elementary objectives.

As can be observed, using a threshold equal to 0.85 leads to detection before week 40 based on the work in progress level or the suppliers performance, and before week 30 based on the suppliers quality performance which is itself a sub-objective of the suppliers performance. This early detection makes it possible for decision-makers to adjust the action plan.

\section{Conclusion}

For the control of their performance improvement process, decision-makers have learned to define strategic objectives and action plans and to follow their evolution. The performance expression at the strategic objective level combines the multiple criteria of the sub-objectives by aggregating their performance expression. This paper presents a descriptive framework, relying on mathematical definitions, which unifies the objective declaration and the temporal aspects of the performance expression which is not widely studied in literature. It is based on the break-down of strategic 
objectives as trees of variables associated with the sub-objectives. A set-based representation of a tree is introduced in order to have well-defined functions to globally process trees. Hierarchy, selection and quantification functions are introduced to formally represent the breakdown and the objective temporal trajectories. A depth-first search algorithm is given to compute the performance expression temporal trajectories. It processes the elementary objectives by means of comparison functions, and the other objectives by means of aggregation functions. The hydraulic cylinders manufacturing line of the Bosch Rexroth Company is used to illustrate the advantage of taking into account the performance expression temporal trajectories. It has been shown that thresholds on the temporal performance trajectories make it possible for an early detection of abnormal behaviour in the action plan. Further studies are undergoing to replace threshold-based detection by more complex features based on the trends of the performance expressions.

\section{Acknowledgments}

The authors would like to thank Vincent Cliville for his early work on the hierarchy and selection functions. His original contribution was helpful to reformulate these concepts in our framework.

\section{References}

[1] M. Bourne, A. Neely, J. Mills, K. Platts, Implementing performance measurement systems: a literature review, International Journal of Business Performance Management 5 (1) (2003) 1-24.

[2] P. Folan, J. Browne, A review of performance measurement: Towards performance management, Computers in Industry 56 (7) (2005) 663-680.

[3] S. S. Nudurupati, U. S. Bititci, V. Kumar, F. T. S. Chan, State of the art literature review on performance measurement, Computers \& Industrial Engineering 60 (2) (2011) 279-290.

[4] A. Neely, M. Gregory, K. Platts, Performance measurement system design: a literature review and research agenda, International Journal of Operations and Production Management 48 (4) (1995) 80-116.

[5] S. A. Melnyk, D. M. Stewart, M. Swink, Metrics and performance measurement in operations management: dealing with the metrics maze, Journal of Operations Management 22 (3) (2004) 209-218.

[6] V. Clivillé, L. Berrah, G. Mauris, Quantitative expression and aggregation of performance measurements based on the MACBETH multi-criteria method, International Journal of Production Economics 105 (1) (2007) 171-189.

[7] L. Fortuin, Performance indicators, why, where and how?, European Journal of Operational Research 34 (1988) 1-9.

[8] V. Popova, A. Sharpanskykh, Modeling organizational performance indicators, Wireless Networks 35 (4) (2010) $505-527$.

[9] C. Lohman, L. Fortuin, M. Wouters, Designing a performance measurement system: A case study, European Journal of Operational Research 156 (2) (2004) 267-286.

[10] J. Browne, J. Devlin, A. Rolstadas, B. Andersen, Performance measurement: the ENAPS approach, International Journal of Business Transformation 69 (2) (1997) 73-84.

[11] M. Lebas, Performance measurement and performance management, International Journal of Production Economics 1-3 (1995) 23-35.

[12] R. L. Keeney, Value-Focused thinking, A path to Creative Decisionmaking, Harvard University Press, 1992.

[13] P. Folan, J. Browne, H. Jagdev, Performance: Its meaning and content for today's business research, Computers in Industry 58 (7) (2007) 605-620.

[14] A. Bhimani, Contemporary Issues in Management Accounting, Oxford University Press, USA, 2006.

[15] A. Neely, C. Adams, M. Kennerley, The Performance Prism: The Scorecard for Measuring and Managing Business Success, Financial Times Prentice Hall, London, 2002.

[16] P. Garengo, S. Biazzo, U. S. Bititci, Performance measurement systems in smes: A review 
for a research agenda, International Journal of Management Reviews 7 (1) (2005) 25-47.

[17] L. Shah, Value/risk based performance evaluation of industrial systems, Ph.D. thesis, Arts et Métiers ParisTech - Centre de Metz (2012).

[18] S. Globerson, Issues in developing a performance criteria system for an organisation, International Journal of Production Research 23 (4) (1985) 639-646.

[19] U. S. Bititci, A. S. Carrie, L. McDevitt, Integrated performance measurement systems: a development guide, International Journal of Operations \& Production Management 17 (5) (1997) 522-534.

[20] R. Kaplan, D. Norton, The Balanced Scorecard: Translating Strategy into Action, Harvard Business School Press, Boston, 1996.

[21] L. Berrah, G. Mauris, F. Vernadat, Information aggregation in industrial performance measurement: rationales, issues and definitions, International Journal of Production Research 42 (20) (2004) 4271-4293.

[22] U. S. Bititci, Modelling of performance measurement systems in manufacturing enterprises, International Journal of Production Economics 42 (1995) 137-147.

[23] U. S. Bititci, P. Suwignjo, A. S. Carrie, Strategy management through quantitative modelling of performance measurement systems, International Journal of Production Economics 69 (1) (2001) $15-22$.

[24] P. Suwignjo, U. Bititci, A. Carrie, Quantitative models for performance measurement system, International Journal of Production Economics 64 (1-3) (2000) 231-241.

[25] A. M. Ghalayini, J. S. Noble, T. J. Crowe, An integrated dynamic performance measurement system for improving manufacturing competitiveness, International Journal of Production Economics 48 (3) (1997) 207-225.

[26] K. Cross, R. Lynch, The "SMART" way to define and and sustain success, National Productivity Review 1 (1988) 23-33.

[27] P. Kueng, Process performance measurement system: A tool to support process-based organizations, Total Quality Management 11 (1) (2000) 67-85.

[28] L. Berrah, G. Mauris, L. Foulloy, A. Haurat, Fuzzy performance indicators for manufacturing processes, in: L. Reznik, V. Dimitrov, J. Kaprzyk (Eds.), Fuzzy System Design: Social and Engineering Applications, Vol. 17, Physica-Verlag, 1998, pp. 225-248.

[29] L. Berrah, G. Mauris, A. Haurat, L. Foulloy, Global vision and performance indicators for an industrial improvement approach, Computers in Industry 43 (3) (2000) 211-225.

[30] R. Ribeiro, Fuzzy multiple attribute decision making: A review and new preference elicitation techniques, Fuzzy Sets and Systems 78 (2) (1996) 155-181.

[31] Y. Ducq, B. Vallespir, G. Doumeingts, Coherence analysis methods for production systems by performance aggregation, International Journal of Production Economics 1 (2001) 23-37.

[32] L. Zadeh, Precisiation of meaning via translation into PRUF, in: L. Vaina, J. Hintikka (Eds.), Cognitive Constraints on Communication, Dordrecht: Reidel, 1984, pp. 373-402.

[33] L. Zadeh, Fuzzy logic = computing with words, IEEE Transactions on Fuzzy Systems 2 (1996) 103-111.

[34] L. Zadeh, A note on web intelligence, world knowledge and fuzzy logic, Data \& Knowledge Engineering 50 (2004) 291-304.

[35] W. Ashby, An introduction to cybernetics, Chapman and Hall, London, 1956.

[36] T. Malone, The future of work, Harvard Business School Press, Boston, MA, 2004.

[37] H. Mintzberg, Tracking Strategies: towards a general theory of strategy formation, Oxford University Press, USA, 2008.

[38] C. Pina, A. Rego, Complexity, simplicity, simplexity, European Management Journal 2 (2010) 85-94.

[39] H. A. Simon, Y. Iwasaki, Causal ordering, comparative statics, and near decomposability, Journal of Econometrics 39 (1-2) (1988) 149-173.

[40] A. Neely, The performance measurement revolution: why now and what next?, International Journal of Operations \& Production Management 19 (2) (1999) 205-228. 
[41] J. Mustajoki, R. Hämäläinen, M. Lindstedt, Using intervals for global sensitivity and worstcase analyses in multiattribute value trees, European Journal of Operational Research 174 (2006) 278-292.

[42] M. Pöyhönen, H. Vrolijk, R. Hämäläinen, Behavioral and procedural consequences of structural variation in value trees, European Journal of Operational Research 134 (2001) 216-227.

[43] T. Saaty, A scaling method for priorities in hierarchical structures, Journal of Mathematical Psychology 15 (1977) 234-281.

[44] T. Saaty, Fundamentals of the Analytic Hierarchy process, RWS Publications, 2000.

[45] T. Saaty, The analytical hierarchy and analytic network process for the measurement of intangible criteria and for decision-making, in: J. Figueira, S. Greco, M. Ehrgott (Eds.), Multiple Criteria Decision Analysis. State of the Art Surveys, Springer, 2005, pp. 345-407.

[46] M. Mesarovic, D. Macko, Y. Takahara, Theory of Hierarchical Multilevel Systems, Academic Press, New York, 1970.

[47] A. Kaklauskas, E. Zavadskas, V. Trinkunas, A multiple criteria decision support on-line system for construction, Engineering Applications of Artificial Intelligence 2 (2007) 163-175.

[48] S. P. Santos, V. Belton, S. Howick, Adding value to performance measurement by using system dynamics and multicriteria analysis, International Journal of Operations \& Production Management 11 (2002) 1246-1272.

[49] R. R. Rodriguez, J. J. A. Saiz, A. O. Bas, Quantitative relationships between key performance indicators for supporting decision-making processes, Computers in Industry 60 (2) (2009) 104-113.

[50] J. S. Dyers, Maut - multiattribute utility theory, in: J. Figueira, S. Greco, M. Ehrgott (Eds.), Multiple Criteria Decision Analysis. State of the Art Surveys, Springer, 2005.

[51] Y. Siskos, E. Grigoroudis, N. F. Matsatsinis, Uta methods, in: J. Figueira, S. Greco, M. Ehrgott (Eds.), Multiple Criteria Decision Analysis. State of the Art Surveys, Springer, 2005.

[52] D. J. Johnson, A framework for reducing manufacturing throughput time, Journal of Manufacturing Systems 22 (4) (2003) 283-298.

[53] L. Berrah, J. Montmain, G. Mauris, V. Clivillé, Optimising industrial performance improvement within a quantitative multi-criteria aggregation framework, International Journal of Data Analysis Techniques and Strategies 3 (1) (2011) 42-65. 